\title{
O PENSAMENTO DE PAULO FREIRE E A EDUCAÇÃO DE JOVENS E ADULTOS NO BRASIL: A OMISSÃO CONSENTIDA DA POLÍTICA EDUCACIONAL
}

\author{
THE THOUGHT OF PAULO FREIRE AND THE YOUNG AND ADULTS EDUCATION IN BRAZIL: THE CONSENTE \\ OMISSION OF EDUCATIONAL POLICY \\ EL PENSAMIENTO DE PAULO FREIRE Y LA EDUCACIÓN DE JÓVENES Y ADULTOS EN BRASIL: LA OMISIÓN \\ CONSENTIDA DE LA POLÍTICA EDUCATIVA
}

\author{
AZEVEDO, Márcio Adriano de ${ }^{1}$ \\ SOUZA, Francisco das Chagas Silva ${ }^{2}$
}

\begin{abstract}
RESUMO
O artigo tem como objetivo discutir a educação de jovens e adultos no Brasil à luz do marco legal da política educacional e dos programas governamentais, abordando alguns contrapontos com base nas ideias freireanas. Como opção teórico-metodológica, adotamos os procedimentos da revisão bibliográfica e da análise documental. No que diz respeito às concepções, em que pese os dispositivos legais e institucionais acenarem à garantia do direito à educação, não se percebe, na prática, sobretudo das ações governamentais, quaisquer fundamentos na educação libertária. É imperativo, entre outras iniciativas, substituir a ideia de idade própria por educação permanente, a qual confere autonomia e a libertação dos sujeitos, superando também o legado histórico de se formular e implementar ações voltadas à educação bancária, as quais não estimulam a curiosidade, o espírito crítico, criativo e emancipatório.
\end{abstract}

Palavras-chave: Paulo Freire. Educação de Jovens e Adultos. Política educacional.

\section{ABSTRACT}

The article aims to discuss the Young and Adult Education considering the legal framework of the educational policy and the government programs, approaching some counterpoint based on Freire's idea. As a theoretical-methodological option, we adopted the procedures of bibliographical revision and documental analysis. As it refers to the concerned conceptions, even though the legal and institutional arrangements guarantees the right to education, in practice, it can't be notice, above all, the government actions do not reveal any basis ilibertarian education. It's imperative, among other initiatives, to replace the idea of own age by permanent education, which grants to autonomy and liberation of subjects, overcoming also the historical legacy of formulating and implementing actions aimed to banking education, which do not stimulates curiosity and the critical, creative and emancipator spirit.

Key words: Paulo Freire. Young and Adults Education. Educational Policy.

\section{RESUMEN}

El artículo tiene como objetivo discutir la educación de los jóvenes y adultos en Brasil a la luz del marco jurídico de la política de educación y programas de gobierno, que abordan algunos contrapuntos sobre la base de las ideas freireanas. Como aproximación procedimientos teóricos y metodológicos adoptados de la revisión bibliográfica y análisis de documentos. Con respecto a las concepciones, a pesar de las disposiciones legales e institucionales acenarem para garantizar el derecho a la educación, no está claro en la práctica, sobre todo de las acciones del gobierno, no hay motivos en educación libertaria. Es imprescindible, entre otras iniciativas, para reemplazar la idea de la edad adecuada para el aprendizaje permanente, lo que le da la autonomía y la libertad de las personas, también para superar la herencia histórica para formular e implementar acciones dirigidas a la educación bancaria, que no estimulan la curiosidad, el pensamiento crítico, creativo y emancipador.

Palabras clave: Paulo Freire. Educación de los jóvenes. Política educativa.

\footnotetext{
1 Instituto Federal de Educação, Ciência e Tecnologia do Rio Grande do Norte - IFRN - Natal - Rio Grande do Nortel - Brasil 2 Instituto Federal de Educação, Ciência e Tecnologia do Rio Grande do Norte - IFRN - Natal - Rio Grande do Nortel - Brasil
} 


\section{PALAVRAS INICIAIS: PARA COMPREENDER A EDUCAÇÃO DE JOVENS E ADULTOS}

Um elemento essencial para assimilarmos o tema que nos propomos a discutir neste artigo _ a "educação de pessoas jovens e adultas" _ é nos atermos para o fato de que ele não nos encaminha apenas a uma questão de especificidade etária, mas também, e principalmente, a uma questão de especificidade cultural. Assim, como destaca Oliveira (2007, p. 63): "[...] esse território da educação não diz respeito a reflexões e ações educativas dirigidas a qualquer jovem ou adulto, mas delimita um determinado grupo de pessoas relativamente homogêneo no interior da diversidade de grupos culturais da sociedade contemporânea".

De acordo com a autora em tela, esses jovens e adultos não formam um grupo com características comuns a outros de sua faixa etária. Eles são sujeitos excluídos da escola, mas que foram inseridos em cursos supletivos em fases mais adiantadas da escolaridade e que agora têm a oportunidade de concluir a educação básica. Assim, para ela, ponderar acerca de como esses jovens e adultos pensam e aprendem "[...] envolve, portanto, transitar pelo menos por três campos que contribuem para a definição de seu lugar social: a condição de 'não-crianças', a condição de excluídos da escola e a condição de membros de determinados grupos culturais" (OLIVEIRA, 2007, p. 64).

Arroyo (2011) destaca a preocupação dos estudos em configurar a educação de jovens e adultos. Salienta que, por décadas, os alunos dessa modalidade foram vistos apenas como aqueles que tiveram trajetórias escolares truncadas, incompletas. Assim, para ele:

\footnotetext{
Urge ver mais do que alunos ou ex-alunos em trajetórias escolares. Vê-los jovens-adultos em suas trajetórias humanas. Superar a dificuldade de reconhecer que, além de alunos ou jovens evadidos ou excluídos da escola, antes do que portadores de trajetórias escolares truncadas, eles e elas carregam trajetórias perversas de exclusão social, vivenciam trajetórias de negação dos direitos mais básicos à vida, ao afeto, à alimentação, à moradia, ao trabalho e à sobrevivência. Negação até do direito a ser jovem. As trajetórias escolares truncadas se tornam mais perversas porque se misturam com essas trajetórias humanas. Se reforçam mutuamente. A EJA como política pública adquire uma nova configuração quando equacionada na abrangência das políticas públicas que vêm sendo exigidas por essa juventude. (ARROYO, 2011, p. 24).
}

Apesar da exclusão, sinais das preocupações da sociedade com esses jovens e adultos que têm direito à educação básica estão presentes em propostas voltadas para esse público por meio da educação não formal de adultos, geralmente vinculadas a organizações não governamentais, igrejas, partidos políticos, sindicatos, dentre outros (GADOTTI, 2001a, ARROYO, 2011).

No entanto, importa destacar que essa educação não formal de jovens e adultos não é algo novo, embora esse fato não a desmereça. Haddad e Di Pierro (2007), ao oferecer uma visão panorâmica da história da escolarização de jovens e adultos no Brasil, ressaltam que tanto no passado quanto no presente, processos educativos voltados a jovens e adultos se desenvolvem fora de ambientes escolares, realizando-se na família, nos locais de trabalho, nos espaços de convívio sociocultural e lazer, nas instituições religiosas e, nos dias atuais, também com o concurso dos meios de informação e comunicação a distância. Por essa razão, historicizar um universo tão plural de 
práticas formativas não é algo simples: "implicaria sério risco de fracasso, pois a educação de jovens e adultos, compreendida nessa acepção ampla, estende-se por quase todos os domínios da vida social" (2007, p. 85).

Por outro lado, o envolvimento da sociedade tem feito com que, aos poucos, no Brasil "O conceito de educação de adultos [venha] se movendo na direção de Educação Popular na medida em que a realidade começa a fazer algumas exigências à sensibilidade e à competência científica dos educadores e das educadoras" (FREIRE, 2001, p. 15). Para Gadotti (2001a, p. 30), essa mudança resulta do "[...] processo sistemático de participação na formação, fortalecimento e instrumentalização das práticas e dos movimentos populares, com o objetivo de apoiar a passagem do saber popular ao saber orgânico".

Para Freire (2001), a educação de adultos popular é mais abrangente do que as demais, visto que, segundo explicita o autor, alguns programas vinculados aos sistemas oficiais de educação, sejam de alfabetização ou de profissionalização, "[...] são apenas uma parte do trabalho mais amplo que se sugere quando se fala em Educação Popular" (FREIRE, 2001, p. 16).

No conjunto das experiências sob as diferentes concepções e diretrizes político-administrativas e pedagógicas, ou mesmo com base em relatórios técnicos sobre a educação de jovens e adultos, os estudos de Azevedo (2014), Bandeira (2001), Borges (2001), Di Pierro, Joia e Ribeiro (2001) e Gadotti (2001b) assim podem descrever suscintamente, e sem a pretensão de nos aprofundarmos, as trajetórias e os percursos da educação de jovens e adultos no Brasil, as quais são explicitadas por Azevedo (2014b), sendo a maioria concebidas com as ideias que se aproximam ou se fundamentam daquelas defendidas por Paulo Freire:

a) Campanha de Educação de Adolescentes e Adultos - CEAA (1947);

b) Sistema Rádio Educativo Nacional - SIRENA (1958), que desenvolveu o programa de escolas radiofônicas em todo o País, como decorrência da Campanha de Educação de Adolescentes e de Adultos;

c) Movimento de Cultura Popular - MCP (1960);

d) Centros Populares de Cultura - CPCS da UNE (1961);

e) A campanha De pé no chão também se aprende a ler (1961), criada pela Secretaria Municipal de Natal/RN, na gestão do então prefeito Djalma Maranhão e Moacyr de Góes (Secretário de Educação);

f) Movimento de Educação de Base (MEB), criado pela CNBB, com o apoio do Ministério da Educação (1961); 
g) Movimentos da ação católica, conhecidos como Juventude Agrária Católica (JAC), Juventude Estudantil Católica (JEC), Juventude Independente Católica (JIC), Juventude Operária Católica (JOC), Juventude Universitária Católica (JUC);

h) Ação Popular - AP (1962);

i) Plano Nacional de Alfabetização (1963);

j) Quarenta horas de Angicos, no Rio Grande do Norte (1963), cujo cinquentenário foi celebrado em 2013;

k) CEPLAR - Campanha de Educação Popular (anos de 1960);

1) Movimento Brasileiro de Alfabetização - MOBRAL (1967-1985), o qual se dividiu em: Programa de Alfabetização Funcional, Programa de Educação Integrada, Programa MOBRAL Cultural, Programa de Profissionalização;

m) Serviços de Educação de Jovens e Adultos - SEJA -, implementado em 1989 pela Secretaria Municipal de Porto Alegre;

n) No mesmo período e sob a influência das ideias freireanas, podemos descrever também o movimento das escolas comunitárias de Olinda, em Pernambuco, destacando as experiências da Associação dos Educadores das Escolas Comunitárias;

o) FUNDAÇÃO EDUCAR (1985-1990);

p) Plano Nacional de Alfabetização e Cidadania - PNAC (1990);

q) Movimento de Alfabetização de Jovens e Adultos - MOVA, o qual surgiu em 1989, em São Paulo, sendo idealizado pelo educador popular Pedro Pontual e por Paulo Freire, à época à frente da Secretaria Municipal daquele estado;

r) Comissão Nacional de Educação de Jovens e Adultos (1996);

s) Projeto SESC LER (1998).

Vale ressaltar ainda como marco histórico no âmbito das políticas para jovens e adultos a realização das seis Conferências Internacionais de Educação de Adultos (CONFITEA) ocorridas em continentes e países diferentes, sempre destacando, dentre outros aspectos, a contribuição de Paulo Freire aos processos de educação de adultos ${ }^{4}$.

Assim, como podemos perceber, as iniciativas governamentais ou da sociedade civil quanto à educação de jovens e adultos têm sido muitas. Como ressalta Arroyo (2011, p. 19):

\footnotetext{
${ }^{3}$ Para aprofundar o assunto, sugerimos Germano (1997) e Silva e Sampaio (2013).

${ }^{4}$ Um breve histórico das CONFITEAs pode ser encontrado em um documento produzido pelo MEC, o qual está disponível no site http://forumeja.org.br/go/sites/forumeja.org.br.go/files/breve_historico-confinteas.pdf.
} 
Um campo aberto a qualquer cultivo e semeadura será sempre indefinido e exposto a intervenções passageiras. Pode-se tornar um campo desprofissionalizado. De amadores. De campanhas e de apelos à boa vontade e à improvisação. Um olhar precipitado nos dirá que talvez tenha sido esta uma das marcas da história da EJA: indefinição, voluntarismo, campanhas emergenciais, soluções conjunturais (grifo nosso).

A indefinição, o voluntarismo e as campanhas emergenciais de que fala o autor supracitado tendem a limitar o caráter emancipatório da educação de jovens e adultos, isto porque, com base nos escritos de Freire (1980, 1981, 1996, 2011), a educação (que poderíamos adjetivar como popular) deve ter como fim a transformação do sujeito em agente político. Em outras palavras, no caso da educação de jovens e adultos, essa educação deveria torná-los promotores do seu protagonismo, participantes ativos na transformação do mundo e da sua história, seres autônomos e capazes de se organizar coletivamente na organização de um projeto de sociedade que tenha como elemento central o ser humano. Significa vê-los não como alunos que "se perderam" no processo de educação formal, pois, como salienta Arroyo (2001, p. 25), suas "trajetórias sociais e escolares truncadas não significam sua paralização nos tensos processos de sua formação mental, ética, identitária, cultural, social e política. Quando voltam à escola, carregam esse acúmulo de formação e de aprendizagem".

Em meio aos entraves, lutas e conquistas, podemos demarcar que as ações voltadas à educação para jovens e adultos, por meio dos sistemas oficiais ou educação do sistema, conforme define Gadotti (2001a), respaldam-se, de um lado, no marco legal, estabelecido a partir dos anos de 1980, com a Constituição Federal e, de outro, no conjunto de ações governamentais materializadas em programas e projetos. No que diz respeito às concepções, sobretudo aquelas que fundamentam as políticas e os projetos, parece-nos que há uma omissão consentida em torno de pensamentos mais progressistas, como o de Paulo Freire, razão pela qual trabalhamos com a ideia de omissão consentida.

\section{EDUCAÇÃO DE JOVENS E ADULTOS E OS PROGRAMAS GOVERNAMENTAIS: A (IM)POSSIBILIDADE DE AÇÕES LIBERTÁRIAS}

Ao enfatizar os programas e projetos de alfabetização no Brasil, estudos como os de Soares (2006b) e Di Pierro (2001), e até mesmo documentos oficiais como aqueles produzidos pela Unesco (2008), mostram que, ao longo das últimas quatro décadas, o ensino público de nível básico para a população jovem ou adulta foi caracterizado como um serviço descontínuo. Na verdade, em que pese mencionar os anos de 1950 a 1980, em outros estudos de Di Pierro e Graciano (2003), percebemos que nas décadas subsequentes, quais sejam, os anos de 1990 e os de 2000, as iniciativas públicas governamentais e não governamentais - na maioria dos casos, continuaram a promover ações desconcentradas, assistencialistas e descontínuas para os jovens e adultos no Brasil, visto que a União transferiu suas responsabilidades aos estados e municípios, sem oferecer as condições objetivas e efetivas. Para Soares (2006a, p. 125): 
A municipalização, situação conhecida como a transferência para o município de encargos de políticas públicas, trouxe um excesso de atribuições que sobrecarregou e comprometeu a capacidade dos municípios em dar respostas às demandas sociais. Além de muitos municípios [como Canguaretama] não se encontrarem preparados ou mesmo equipados o suficiente para assumirem os encargos que lhes foram atribuídos (Destaque da autora).

Para além dos aspectos legais da política educacional brasileira, há um componente indispensável à educação, sobretudo para quem trabalha com jovens e adultos, quais sejam por meio de processos que visam à conscientização, ao que é dialógico e à politicidade (FREIRE, 2014; FREIRE; GUIMARÃES, 2011; FREIRE; SHOR, 2011). Nesse sentido, como afirma Torres (2014, p. 9192):

[...] enquanto a educação que se baseia na conscientização de um processo humanista de libertação tem que ser, fundamentalmente, uma operação de desvelamento do mundo, a educação para a domesticação tem que ser, fundamentalmente, um processo de mitologização. Por quê? Por que no dia em que as forças do poder e da dominação que governam a ciência e a tecnologia conseguirem descobrir um meio de matar a intencionalidade e o caráter ativo da consciência, o que a faz perceber-se a si mesma, já não poderemos falar em libertação.

Logo, percebemos a mão dupla do desafio que se impõe ao processo educativo, visto que historicamente além de não possuirmos o sistema educacional orientado para concepções e organização libertárias, a formação acadêmica em nível de graduação ou formação inicial também não tem possibilitado o aprofundamento em subcampos como a educação de jovens e adultos. $\mathrm{Na}$ perspectiva freireiana, em conformidade com o Instituto Pichon-Riviére (1991, p. 31):

\begin{abstract}
Cabe ao educador aprender com o educando qual é a sua realidade, obtendo assim os elementos básicos do processo de educação, de maneira que o educando possa então aprender com o educador, que dispõe de determinados instrumentos, determinadas experiências que, colocadas a serviço do grupo, podem permitir adquirir o conhecimento de si mesmo e de sua realidade, o que antes não tinha.
\end{abstract}

A ideia de que o educador deve aprender com o educando rompe com o centralismo do processo educativo, no sentido de que o professor é o centro e o educando o receptor, o que Paulo Freire chamaria de educação bancária. Para romper com essa perspectiva historicamente construída, é necessário que os sistemas e práticas observem concepções e estruturas mais democráticas. Para Lima (2013, p. 86):

\footnotetext{
Esta prática educativa democrática, antidiscriminatória, uma prática "educativo-progressista" (como the chamou o nosso autor), orientada para a realização dos educandos como seres livres e conscientes, para a aproximação crítica entre a escola e a vida, currículo e experiência social dos sujeitos [...] formação democrática e exercício efetivo de práticas democráticas e participativas na escola, ao comprometer-se assim com a emancipação e a autonomia, revela-se uma pedagogia da autonomia (Grifos do autor).
} 
Isso é um desafio tanto para a educação quanto para as particularidades, como a EJA, sobretudo porque as suas ofertas, além de se configurarem em programas e projetos transitórios - o que dificulta a garantia do direito constitucional -, geralmente são delegados também a instituições que não possuem a devida tradição e a experiência com a EJA.

A título de ilustração, podemos destacar que, na lógica privatista perseguida pelos dois governos de Fernando Henrique Cardoso, a partir dos anos de 1990, o Programa Alfabetização Solidária, o Plano Nacional de Qualificação do Trabalhador (PLANFOR) e o Programa de Formação de Atendentes de Enfermagem (PROFAE) geralmente privilegiaram ações compensatórias, aligeiradas e minimalistas do ponto de vista da alfabetização e de formações sólidas para a elevação dos níveis de escolaridade, bem como de inserção para o mundo do trabalho (COSTA, 2003). Vale destacar que, no contexto de lutas dos movimentos sociais nos anos de 1990, o Programa Nacional de Educação na Reforma Agrária (PRONERA) foi uma conquista plausível para jovens e adultos no Brasil. Nessa perspectiva, identificamos que, conforme Di Pierro (2001, p. 327):

\begin{abstract}
Ao longo da segunda metade dos anos 1990, novos agentes da sociedade civil, como centrais sindicais de trabalhadores e fundações empresariais, incorporaram-se ao rol dos provedores de programas de Educação Básica de Jovens e Adultos. Nesse mesmo período, a palavra parceria incorporou-se ao vocabulário desse campo educativo, passando a ocupar lugar de destaque no discurso dos mais diversos atores sociais e agentes governamentais. A noção de parceria passou a ser utilizada para definir tanto a relação contratual estabelecida entres governos estaduais e fundações privadas que produzem programas de educação pela TV, quanto para designar convênios mantidos por governos municipais ou estaduais com organizações comunitárias para o desenvolvimento de movimentos de alfabetização de jovens e adultos.
\end{abstract}

Nos anos 2000 e, em particular, nos mandatos do presidente Luís Inácio Lula da Silva, estudos ressaltam que, apesar de alguns avanços como a criação da Diretoria de Políticas para a Educação de Jovens e Adultos no âmbito da Secretaria de Educação Continuada, Alfabetização e Diversidade (SECAD/MEC) 5 e do Programa Nacional de Integração da Educação Profissional com a Educação Básica na Modalidade de Jovens e Adultos (PROEJA), inclusive reconhecido pela UNESCO (2008) como uma importante iniciativa governamental, outras iniciativas como o Brasil Alfabetizado, Programa Nacional de Inclusão de Jovens (PROJOVEM) e o Escola de Fábrica, bem como o Exame Nacional de Certificação de Competências, realizado pelo Instituto Nacional de Estudos e Pesquisas Educacionais (INEP), inscrevem-se naquelas iniciativas de caráter compensatório e descontínuo (CARVALHO, 2013; FRIGOTTO; CIAVATTA; RAMOS, 2005; RUMMERT; VENTURA, 2007).

Tais perspectivas, além de serem contraditórias ao que a sociedade vem discutindo nos diferentes espaços públicos de debates, como nos Fóruns Estaduais e nos Encontros Nacionais de Educação de Jovens e Adultos (ENEJA), também se distanciam das orientações de organismos como a UNESCO (2010), visto que, de acordo com esse órgão (2010, p. 06):

\footnotetext{
5 Atualmente, denomina-se Secretaria de Educação Continuada, Alfabetização, Diversidade e Inclusão (SECADI/MEC).
} 
As crescentes exigências de conhecimentos e habilidades para a inserção no mundo do trabalho, na economia e na vida cidadã na atual sociedade do conhecimento impõem a ampliação da escolaridade dos jovens, bem como do acesso à educação e formação técnica e profissional. Mostra o Relatório de Monitoramento Global de EPT 2010 que os países desenvolvidos estão próximos de universalizar a educação secundária e têm avançado na oferta de educação e formação técnica e profissional nesse nível ou na educação superior. Para os demais países, entretanto, essas metas representam ainda desafios, às vezes, de grande monta (Grifos nossos).

De fato, o próprio documento de monitoramento da UNESCO (2008) mostra que o compromisso do Brasil de atingir a meta de $50 \%$ na redução do analfabetismo de jovens e adultos até 2015 já não seria possível e que a perspectiva seria postergada para 2015, caso os programas e as demais iniciativas não descontinuassem, o que não vem ocorrendo nem para a elevação dos níveis educativos como para a inserção ao mundo do trabalho, conforme mostram os estudos organizados por Soares (2006b) e Pinheiro e Barbosa Junior (2010).

Cabe ressaltar aqui que os Fóruns ${ }^{6}$ Estaduais de Educação de Jovens e Adultos são importantes espaços sociopolíticos para a intensificação das lutas e dos debates sobre as problemáticas que cercam essa modalidade educativa, em particular as das políticas públicas. $O$ primeiro Fórum EJA foi instituído no Rio de Janeiro, em 1996, durante encontro com educadores e pesquisadores envolvidos com a educação de jovens e adultos. Atualmente, todos os estados da Federação já possuem o Fórum, sendo 26 estaduais, 1 distrital e 50 regionais (URPIA, 2009). De acordo com Paiva (2009, p. 62), os Fóruns de EJA “[...] têm resistido, como uma dessas alternativas, aos desdobramentos constantes que obstruem os caminhos em construção na EJA, sedimentando, com a própria matéria que desaba, novas fundações".

No que diz respeito ao marco legal para a educação de jovens e adultos no Brasil, percebemos que a Constituição Federal de 1988, também intitulada de Constituição Cidadã, dispõe sobre a educação como direito e obrigatoriedade escolar, refletindo-se na legislação educacional brasileira. Isso foi importante, porque recuperou o conceito de educação como direito público subjetivo, abandonado desde a década de 1930, conforme enfatiza Paiva (2009). Isso foi ratificado pela Lei de Diretrizes e Bases da Educação Nacional (BRASIL, 1996), a qual reiterou o direito à educação, os direitos constitucionais para a população jovem e adulta (Art. $4^{\circ}$ ).

Quanto às concepções, em que pese os dispositivos legais e institucionais que acenam quanto à garantia do direito à educação, não se percebe na prática, sobretudo das ações decorrentes dos sistemas oficiais de educação, quaisquer fundamentos na educação libertária. Nos parece que a educação de jovens e adultos no Brasil indica um processo muito para sujeitá-los às ações descontínuas e de negação do direito, do que para emancipá-lo e conscientizá-lo política e humanamente, por meio de processos que Ihes conferem a necessária autonomia como explicita Freire (1980; 1996).

\footnotetext{
${ }^{6}$ Para aprofundar, indicamos Soares (2004).
} 
Ademais, a educação de jovens e adultos, de acordo com a LDB, é uma modalidade da Educação Básica, nos seus níveis fundamentais e médio, sendo reconhecida como direito público subjetivo, rompendo assim com a ideia de ensino supletivo, conforme observa Paiva (2009). Entretanto, em que pesem as garantias constitucionais, tanto Paiva (2009) quanto Costa (2013) observam retrocessos no que diz respeito aos direitos, visto que a Emenda Constitucional 14/96 alterou o inciso I do Art. 208 da Constituição Federal, induzindo que o ensino fundamental possa atender aos jovens e adultos, mas não em caráter de obrigatoriedade, sob o argumento de que não se podem obrigar adultos e jovens além dos 14 anos a frequentar a escola, se não o fizeram na idade própria ${ }^{7}$. "Não resta dúvida de que a emenda 14/96, foi um duro golpe contra o processo inclusivo de jovens e adultos ao sistema educativo, uma vez que tirou o compromisso do Estado com essa população" (COSTA, 2013, p. 76).

Com a criação do Fundo de Manutenção e Desenvolvimento do Ensino Fundamental e de Valorização do Magistério (FUNDEF), o financiamento da educação foi focalizado no ensino fundamental, comprometendo outros níveis e modalidades de educação, como a infantil e a de jovens e adultos. Em dezembro de 2006, na perspectiva de superar os impasses causados pelo FUNDEF, foi aprovada a Emenda Constitucional 53, que criou o Fundo de Manutenção e Desenvolvimento da Educação Básica e Valorização dos Profissionais da Educação (FUNDEB). Nesse sentido, partia-se do princípio de que o FUNDEB iria abranger todas as etapas e modalidades da educação básica, criando a expectativa de que a educação de jovens e adultos seria contemplada com financiamento específico e que os investimentos obedeceriam a critérios de equidade. Entretanto, para Costa (2013, p. 79):

[...] isso não aconteceu, pois a Lei Federal $\mathrm{N}^{\circ}$ 11.494/2007, que regulamentou o FUNDEB, acabou oficializando a histórica discriminação sofrida pela EJA. Isso se explica porque o valor aluno/ano destinado a EJA em 2007 era de $\mathrm{R} \$ 662,40$, inferior 42,86\% em relação ao aluno de ensino fundamental e $71,43 \%$ em relação ao aluno de ensino médio. Para sacramentar a injustiça oficial, a mesma lei estabeleceu ainda que a apropriação dos recursos do FUNDEB, em cada estado para a EJA, será de apenas $15 \%$ do total de recursos, que são explicitamente insuficientes para garantir um ensino de qualidade.

As limitações à educação de jovens e adultos também são identificadas no Plano Nacional de Educação (2001-2010). Inclusive, após os vetos presidenciais aos recursos em 2001, as metas e as diretrizes para essa modalidade educativa foram comprometidas no que diz respeito à construção social do direito, conforme observa Paiva (2009). Mesmo com o FUNDEB e com o debate sobre o novo Plano Nacional de Educação (2014-2024), os desafios ainda estão postos tanto aos processos de

\footnotetext{
${ }^{7}$ Essa ideia contrapõe-se à ideia de que a educação é um processo que se desenvolve ao longo da vida, conforme ressaltam os estudos de Delors (2003), e de que a formação humana deve ser constante, visto a inconclusão humana (FREIRE, 2011). Na verdade, o que percebemos é que a ideia de "[...] formação e a aprendizagem ao longo da vida chegam a ser objecto de um tão profundo processo de instrumentalização com vista à eficácia econômica e à performatividade competitiva que parecem frequentemente reduzidas a estratégias vocacionalistas e a técnicas de gestão de recursos humanos, pouco ou nada se assemelhando a formas e processos de educação (LIMA, 2007, p. 20). Ademais, "[...] Além da questão econômica, a marginalização da educação de adultos incide num grave erro sociológico, ao supor que o adulto é culpado por sua própria ignorância" (PRADO, 2012, p. 83).
} 
alfabetização e de letramento quanto de inserção ao mundo do trabalho de jovens e adultos no Brasil. Observamos assim que, segundo Di Pierro (2010, p. 944):

\begin{abstract}
O capítulo dedicado à EJA no PNE aprovado pelo Congresso na forma da Lei n. 10.172/2001 teceu um diagnóstico que reconheceu a extensão do analfabetismo absoluto e funcional e sua desigual distribuição entre as zonas rural e urbana, as regiões brasileiras, os grupos de idade, sexo e etnia. O Plano admitia ser insuficiente apostar na dinâmica demográfica e atuar apenas junto às novas gerações, propondo que as ações de escolarização atingissem também os adultos e idosos. Nas diretrizes, o PNE aderiu à concepção de educação continuada ao longo da vida, mas priorizou a atenção ao direito público subjetivo dos jovens e adultos ao ensino fundamental público e gratuito.
\end{abstract}

A autora destaca que as políticas públicas decorrentes do Plano Nacional de Educação (20142024) devem conferir materialidade a ideias mais apropriadas de alfabetização e educação básica com qualidade social, implicando assim a necessidade de articular devidamente as oportunidades de qualificação profissional e de acesso às novas tecnologias da comunicação e da informação. Para tanto, é necessário ampliar o financiamento destinado à educação de jovens e adultos e superar a situação de despreparo e desvalorização profissional dos educadores que a ela se dedicam, bem como rever os currículos e as práticas pedagógicas voltadas a essa modalidade educativa.

Ainda no que diz respeito ao marco legal, ressaltamos também a aprovação das Diretrizes Curriculares Nacionais para a EJA, conforme o Parecer da Câmara de Educação Básica, n 11/2000, nas quais foram estabelecidas as três funções, quais sejam: reparadora, equalizadora e qualificadora, sendo esta última de extrema importância, superando assim o caráter compensatório na educação de jovens e adultos, além de retomar a ideia de educação permanente (CARVALHO, 2009). Mas para se conceber a EJA numa perspectiva mais democrática ou freireana, se requer, entre outros aspectos, conceber o currículo na racionalidade emancipatória, ou seja, é imprescindível compreendê-lo "não como um produto pronto, acabado, para ser consumido, mas como um processo em constante construção, que se faz e se refaz. Fundamentalmente, como um caminho onde a emancipação dos actores que interagem no processo educativo é condição para a sua construção" (SAUL, 2006, p. 155).

No contexto mais contemporâneo do governo Dilma Roussef, além da continuidade das iniciativas implementadas por Luís Inácio Lula da Silva, como o Programa Brasil Alfabetizado e o PROEJA, considerável parte das ações de qualificação profissional voltadas aos jovens e adultos decorrem do Programa Nacional de Acesso ao Ensino Técnico e Emprego (PRONATEC), instituído pela Lei $n^{\circ} 12.513$, de 26 de outubro de 2011.

Contudo, a ideia exclusivamente centrada na formação da mão-de-obra não corresponde ao que propõe o pensamento progressista em torno da educação de jovens e adultos, isto é, o da importância da luta e da pressão dos movimentos sociais e sindicais junto ao Estado, conforme ressalta Torres (2001) e o próprio pensamento freireano (FREIRE, 1981), na perspectiva do desejo utópico de se vislumbrar a educação com enfoque central no ser humano, como possibilidade de transformação e de libertação, as quais não ocorrem sem a formulação e a implementação de políticas públicas de Estado, garantindo assim os princípios constitucionais do direito à educação pública, 
gratuita e de qualidade social, conforme a sociedade vem defendendo nos diferentes espaços, como nos Fóruns de EJA, nos ENEJA e no âmbito das Conferências Nacionais de Educação (2009; 2014).

É imperativo superar ideias preconceituosas de que o sujeito da educação de jovens e adultos é aquele estigmatizado de atrasado, irregular, fora da idade própria. Nessa direção, Paiva (2009) problematiza, ao observar que as iniciativas governamentais e não governamentais, salvo os movimentos de base, funcionaram na maioria das vezes induziu ao estigma. Para ela (2009, p. 42): "A ferida, a chaga; erradicação, extirpar o mal, mancha negra, vergonha nacional são muitas das expressões que acompanham não apenas o imaginário social, mas estão postas em planos, legislações, cartas magnas".

\section{CONSIDERAÇÕES FINAIS}

Ao problematizarmos e discutirmos acerca do pensamento de Paulo na educação de jovens e adultos, com enfoque na política educacional brasileira, vimos que o seu legado tanto pode ser identificado nas ideias quanto nas diferentes iniciativas, as quais destacamos. Por outro lado, percebemos também que as ideias e os fundamentos da política educacional brasileira, em particular aqueles voltados à educação de jovens e adultos, em que pesem as conquistas sociais e as prerrogativas constitucionais, induziram muito mais à sujeição e à negação dos direitos, por meio de políticas e projetos descontínuos, do que à garantia de processos emancipatórios, preocupados com a autonomia e a conscientização dos sujeitos.

A educação de jovens e adultos preocupada com os sujeitos de direitos e fundamentada no pensamento freireano deve superar ideias minimalistas ainda presentes no seio da política educacional brasileira. É imperativo, entre outras iniciativas, substituir a ideia de idade própria por educação permanente, a qual confere autonomia e a libertação dos sujeitos, superando também o legado histórico de se formular e implementar ações voltadas à educação bancária, as quais não estimulam a curiosidade, o espírito crítico, criativo e emancipatório. Do contrário, a política educacional continuará a promover a omissão consentida de importantes pensamentos e pensadores, como Paulo Freire.

\section{REFERÊNCIAS}

1. ARROYO, Miguel Gonzáles. Educação de jovens e adultos: um campo de direitos e de responsabilidade pública. In: SOARES, Leôncio; GIOVANETTI; Maria Amélia; GOMES, Nilma Lima (Orgs). Diálogos na Educação de Jovens e Adultos. 4. ed. Belo Horizonte: Autêntica, 2012. p. 1950. 
2. AZEVEDO, Márcio Adriano de. (Coord.). Indicadores para a qualidade social na educação de jovens e adultos no contexto da diversidade: relatório técnico-científico. João Câmara: CNPq/NEPED-IFRN, 2014a.

3. Trajetórias e percursos das políticas públicas para (jovens e) adultos no Brasil e em Portugal: o direito compensado (Relatório técnico-científico). Pós-doutoramento em Ciências da Educação - Especialidade: Sociologia da Educação. Braga: Universidade do Minho, 2014b.

4. BANDEIRA, Carmen Lúcia B. O movimento das escolas comunitárias de Olinda-Recife. In: GADOTTI, Moacir. ROMÃO, José Eustáquio. (Org.). Educação de Jovens e Adultos: teoria, prática e proposta. 4. ed. São Paulo: Cortez, 2001. p. 101-104.

5. BORGES, Liana. O SEJA de Porto Alegre. In: GADOTTI, Moacir. ROMÃO, José Eustáquio. (Org.). Educação de Jovens e Adultos: teoria, prática e proposta. 4. ed. São Paulo: Cortez, 2001. p. 97100.

6. BRASIL. Lei de Diretrizes e Bases da Educação Nacional. n. 9.394/96, de 20 de dezembro de 1996. Diário Oficial [da] República Federativa do Brasil, Poder Executivo, Brasília-DF, 23 dez. 1996. Disponível em: <http://portal.mec.gov.br/seesp/arquivos/pdf/lei9394_ldbn1.pdf> Acesso em: 4 fev. 2017.

CONFITEA'S - $\quad$ Breve histórico. Disponível em:
$<$ <ttp://forumeja.org.br/go/sites/forumeja.org.br.go/files/breve_historico-confinteas.pdf> Acesso em: 1 fev. 2017.

8. CARVALHO, Marcelo Pagliosa. As políticas para a educação de jovens e adultos nos governos Lula (2003-2010). Disponível em: <http://www.anpae.org.br/iberoamericano2012/Trabalhos/MarceloPagliosaCarvalho_res_int_GT1.p df>. Acesso em: 4 fev. 2013.

9. DI PIERRO, Maria Clara. A educação de jovens e adultos no Plano Nacional de Educação: avaliação, desafios e perspectivas. Educação e sociedade, Campinas, v. 31, n. 112, p. 939-959, jul./set. 2010. . Descentralização, focalização e parceria: uma análise das tendências nas políticas públicas de educação de jovens e adultos. Educação e pesquisa, São Paulo, v. 27, n. 2, p. 321-337, jul./dez. 2001. (Coord.). Alfabetização de jovens e adultos no Brasil: lições da prática. Brasília: UNESCO, 2008. 

Educativa, 2003. Disponível em: <https://alfabetizarvirtualtextos.files.wordpress.com/2011/08/aeducac3a7c3a3o-de-jovens-e-adultos-no-brasil.pdf >. Acesso em: 4 fev. 2017.

13. Brasil. Caderno CEDES, Campinas, n. 55, p. 58-77, nov. 2001.

14. FREIRE, Ana Maria Araújo. (Org.). Paulo Freire - política e educação. São Paulo: Paz e Terra, 2014.

15. FREIRE, Paulo. Ação cultural para a liberdade. 5. ed. Rio de Janeiro: Paz e Terra, 1981. Freire. 3. ed. São Paulo: Moraes, 1980. (Org.). Educação de Jovens e Adultos: teoria, prática e proposta. 4. ed. São Paulo: Cortez, 2001. p. 15-18. e Terra, 1996.

20.

21. FRIGOTTO, Gaudêncio; CIAVATTA, Maria; RAMOS, Marise. A política de educação profissional no governo Lula: um percurso histórico controvertido. Educação e Sociedade, Campinas, v. 26, n. 92, p. 1087-1113, Especial, out. 2005.

22. GADOTTI, Moacir. Educação de Jovens e Adultos: correntes e tendências. In: GADOTTI, Moacir; ROMÃO, José Eustáquio (Org.). Educação de Jovens e Adultos: teoria, prática e proposta. 4. ed. São Paulo: Cortez, 2001a. p. 29-40.

23. . O MOVA-SP: Estado e movimentos populares. In: ; ROMÃO, José Eustáquio. (Org.). Educação de Jovens e Adultos: teoria, prática e proposta. 4. ed. São Paulo: Cortez, 2001b. p. 9196. 

18, n. 59, p. 389-393, ago. 1997. Osmar; IRELAND, Timothy Denis. Educação como exercício de diversidade. Brasília: UNESCO, MEC, ANPEd, 2007. p. 85-128.

26. INSTITUTO PICHON-RIVIÉRE. O processo educativo segundo Paulo Freire e Pichon-Riviére. 3. ed. Trad. Lúcia Mathilde Endlich Orth. Petrópolis: Vozes, 1991.

27. LIMA, Licínio C. Educação ao longo da vida: entre a mão direita e a mão esquerda de Miro. São Paulo: Cortez, 2007.

28. escola pública. 5. ed. São Paulo: Cortez, 2013.

29. OLIVEIRA, Marta Kohl. Jovens e adultos como sujeitos de conhecimento e aprendizagem. In: FÁVERO, Osmar; IRELAND, Timothy D. Educação como exercício de diversidade. Brasília: UNESCO, MEC, ANPEd, 2007. p. 61-84.

30. PAIVA, Jane. Direito formal e realidade social da educação de jovens e adultos. In: SAMPAIO, Marisa Narciso; ALMEIDA, Rosilene Souza. (Org.). Práticas de educação de jovens e adultos: complexidades, desafios e propostas. Belo Horizonte: Autêntica, 2009. p. 21-64.

31. PINHEIRO, Rosa Aparecida; BARBOSA JUNIOR, Walter Pinheiro (Coord.). Estudos e práticas de educação de jovens e adultos na universidade. Natal: KMP, 2010.

32. PRADO, Edna Cristina do. Políticas públicas federais para a educação de jovens e adultos: um olhar sobre a reforma dos anos 90. In: MELO, Adriana Almeida Sales de; PRADO, Edna Cristina do. (Org.). Educação, história, política e educação de jovens e adultos. Maceió: EDUFAL, 2012. p. 77-94.

33. RUMMERT, Sonia Maria; VENTURA, Jaqueline Pereira. Políticas públicas para educação de jovens e adultos no Brasil: a permanente (re)construção da subalternidade - considerações sobre os Programas Brasil Alfabetizado e Fazendo Escola. Educar, Curitiba, n. 29, p. 29-45, 2007.

34. SAUL, Ana Maria. A construção do currículo na teoria e prática de Paulo Freire. IN: APPLE, Michael W; NÓVOA, Antônio. (Orgs.). Paulo Freire: política e pedagogia. Porto: Porto editora, 1998. 
35. SILVA, Francisco Canindé; SAMPAIO, Marisa Narcizo. "50 anos de Angicos: memória presente na educação de jovens e adultos" - "40 horas de Angicos: alguns ensinamentos de seus "coautores". In: REUNIÃO NACIONAL DA ASSOCIAÇÃO DE PESQUISA E PÓS-GRADUAÇÃO EM EDUCAÇÃO - ANPED, 36. 2013. Goiânia: Anais... Goiânia: ANPED, 2013.

SOARES, Leôncio José Gomes. Aprendendo com a diferença: estudos e pesquisas em educação de jovens e adultos. 2. ed. Belo Horizonte: Autêntica, 2006a.

(Org.). Educação de jovens e adultos: o que revelam as pesquisas. Belo Horizonte: Autêntica, 2006b. O surgimento dos Fóruns de EJA no Brasil: articular, socializar e intervir. Revista de EJA, [s.l.], n. 17, maio 2004.

39. TORRES, Carlos Alberto. Diálogo e práxis educativa: uma leitura crítica de Paulo Freire. Trad. Mônica Mattar Oliva. São Paulo: Loyola, 2014. Estado, políticas públicas e educação de adultos. In: GADOTTI, Moacir; ROMÃO, José Eustáquio (Org.). Educação de jovens e adultos: teoria, prática e proposta. 4. ed. São Paulo: Cortez, 2001. p. 19-28.

ORGANIZAÇÃO DAS NAÇÕES UNIDAS PARA A EDUCAÇÃO, A CIÊNCIA E A CULTURA (UNESCO). Monitoramento dos Objetivos de Educação para Todos no Brasil. Brasília: UNESCO; São Paulo: $\quad 2010 . \quad$ Doderna, Disponível em: <http://unesdoc.unesco.org/images/0018/001899/189923por.pdf> Acesso em: 4 fev. 2017. Relatório de monitoramento de educação para todos Brasil 2008: educação para todos em 2015; alcançaremos a meta? Brasília: UNESCO, 2008. Disponível em: <http://unesdoc.unesco.org/images/0015/001592/159294por.pdf> Acesso em: 4 fev. 2017.

43. URPIA, Maria de Fátima Mota. Fórum EJA Bahia: implicação na definição da política pública da educação de jovens e adultos. 2009. 124 f. Dissertação (Mestrado em Políticas Sociais e Cidadania), Universidade Católica de Salvador, Salvador, 2009. 


\section{Márcio Adriano de Azevedo}

Doutor em Educação (UFRN), Pós-Doutor em Sociologia da Educação (Universidade do Minho/Portugal). Professor do Instituto Federal de Educação, Ciência e Tecnologia do Rio Grande do Norte. Professor do Programa de Pós-Graduação em Educação Profissional (IFRN).

\section{Francisco das Chagas Silva Souza}

Licenciado em história. Doutor em educação. Professor dos programas de Pós-Graduação em Ensino (IFRN/UERN/UFERSA) e em educação profissional e tecnológica (Mestrado Profissional em Rede Nacional).

\section{Como citar este documento:}

AZEVEDO, Márcio Adriano de; SOUZA, Francisco das Chagas Silva. O pensamento de Paulo Freire e a Educação de Jovens e Adultos no Brasil: a omissão consentida da Política Educacional. Reflexão e Ação, Santa Cruz do Sul, v. 27, n. 2, abr. 2019. ISSN 1982-9949. Disponível em: <https://online.unisc.br/seer/index.php/reflex/article/view/8960>. Acesso em: doi:https://doi.org/10.17058/rea.v27i2.8960. 